\title{
MEDICINA DA FAMÍLIA, "A HeRANÇA" E O CÂnCER DE MAMA: ENTENDIMENTOS E (DES)CONTINUIDADES DA GENÉTICA PREDITIVA EM CUBA ${ }^{1}$
}

\author{
SAHRA GIBBON ${ }^{23}$
}

\begin{abstract}
RESUMO
Com base nas pesquisas em ciências sociais que examinam a relação entre conhecimento genético, identidade e família, este artigo toma 0 contexto cultural de Cuba como um local de engajamento etnográfico crítico. 0 artigo é baseado em uma pesquisa que contou com a interlocução de mulheres cubanas e profissionais da genética como parte de pesquisa colaborativa que explora o contexto social e cultural das crenças em saúde sobre 0 câncer de mama. Busca-se iluminar as maneiras contrastantes pelas quais o conhecimento genômico relacionado a um risco aumentado de câncer de mama é percebido, comunicado e acionado. Argumenta-se que a importância e o significado particular do risco genético associado ao câncer de mama nesse contexto deve ser examinado em relação às práticas institucionais de longa data relacionadas à prestação de serviços públicos de saúde. 0 foco na 'família', característica da política de saúde pública cubana, oferece pistas ou condições para a expansão do que comumente é descrito como 'genética comunitária', incluindo o agrupamento de detalhes da história familiar para doenças complexas comuns, como o câncer de mama. No entanto, percepções públicas específicas sobre risco relacionadas ao câncer de mama e as dificuldades de discutir abertamente o diagnóstico de câncer na família apontam para desafios muito específicos com relação à tradução e aplicação de intervenções da genética preditiva em Cuba. Em resumo, a dinâmica inter-relação entre saúde pública, percepções de risco ou crenças saúde no que concerne as causas da doença, ou as atitudes tomadas em relação ao diagnóstico de câncer dentro da família apontam, ao mesmo tempo, para continuidades e descontinuidades no modo como as intervenções genômicas associadas ao câncer de mama se desenvolvem como parte de um projeto de assistência à saúde em Cuba, que é dinâmico e, ainda assim, ostensivamente socialista.
\end{abstract}

PALAVRAS-ChAVE

Medicina de família; Genética; Herança; Câncer de mama; Crenças de saúde, Cuba.

\section{FAMILY MEDICINE, 'LA HERENCIA'AND BREAST CANCER; UNDERSTANDING THE (DIS)CONTINUITIES OF PREDICTIVE GENETICS IN CUBA}

\begin{abstract}
Building on social science research examining the relationship between genetic knowledge, identity and the family this paper takes the cultural context of Cuba as a site for critical ethnographic engagement. The paper makes use of research working with a range of Cuban publics and genetic professionals as part of a collaborative research project exploring the social and cultural context of health beliefs about breast cancer. It illuminates the contrasting ways in which genomic knowledge linked to an increased risk of breast cancer is perceived, communicated, and acted upon. It is argued that the particular meaning and significance of genetic
\end{abstract}

\footnotetext{
1 Texto originalmente publicado na Revista Social Science \& Medicine, n.72 (2011) p.1784-1792. Agradecemos Sahra Gibbon e a Revista Social Science \& Medicine pela permissão da tradução desse artigo.

${ }^{2}$ Departamento de Antropologia, University College of London - Reino Unido.

${ }^{3}$ A pesquisa apresentada aqui foi financiada por uma bolsa pós-doutoral do Wellcome Trust, cujo número de referência é WT068432M. Meus sinceros agradecimentos a todas as participantes cubanas que fizeram parte dessa pesquisa e todos aqueles que possibilitaram a finalização dessa pesquisa. Eu também agradeço os pareceristas anônimos que forneceram uma valiosa contribuição ao comentar as primeiras versões desse artigo.
} 
risk linked to breast cancer in this context must be examined in relation to long standing institutional practices relating to public health care provision. The focus on 'the family' in the provision of Cuban health provides a particularly viable foundation for the expansion of what is described as 'community genetics', including the collation of family history details for common complex diseases such as breast cancer. Nevertheless specific public perceptions of risk related to breast cancer and the difficulties of discussing a diagnosis of cancer openly in the family point to the very specific challenges for the translation and application of predictive interventions in Cuba. In summary the dynamic interrelationship between public health, perceptions of risk or health beliefs about the causes of the disease and attitudes towards cancer diagnosis within the family point to both continuities and discontinuities in the way that genomic interventions linked to breast cancer are unfolding as part of a dynamic yet still ostensibly socialist project of health care in Cuba.

\section{KEYWORDS}

Family medicine; genetics; Inheritance; Breast cancer; Health beliefs, Cuba.

\section{MÉDECINE FAMILIALE, "LA HERENCIA " ET CANCER DU SEIN; COMPRENDRE LES (DIS)CONTINUITÉS DE LA GÉNÉTIQUE PRÉDICTIVEÀ CUBA}

\section{RÉSUMÉ}

S'appuyant sur des recherches en sciences sociales qui examinent la relation entre le savoir génétique, l'identité et la famille, cet article considère le contexte culturel de Cuba comme un lieu d'engagement ethnographique critique. L'article est basé sur une enquête menée auprès de femmes et de professionnels de la génétique cubains dans le cadre d'une recherche collaborative explorant le contexte social et culturel des croyances relatives à la santé concernant le cancer du sein. Il cherche à mettre en lumière les différentes manières dont la connaissance génomique liée à un risque accru de cancer du sein est perçue, communiquée et déclenchée. C'est affirmé que la compréhension et l'importance particulière du risque génétique lié au cancer du sein, dans ce contexte, devraient être examinées en relation avec les pratiques institutionnelles de longue date liées à la fourniture de services de santé publique. Mettre l'accent sur la "famille" dans la politique de santé publique cubaine fournit une base particulièrement viable pour développer ce que l'on appelle la "génétique communautaire", notamment en regroupant les détails des antécédents de santé familiale pour des maladies complexes courantes telles que le cancer du sein. Cependant, les perceptions publiques relatifs aux risques liés au cancer du sein et aux difficultés de discuter ouvertement du diagnostic du cancer familial suggèrent des difficultés très spécifiques pour la traduction et l'application d'interventions de génétique prédictive à Cuba. En résumé, l'interdépendance dynamique entre la santé publique, les perceptions du risque ou les croyances de santé concernant les causes de la maladie et les attitudes à l'égard du diagnostic du cancer familial suggèrent des continuités et des discontinuités dans la manière dont les interventions génomiques sont liées au cancer du sein. Il s'agit du développement dans le cadre d'un projet de santé dynamique mais toujours ostensiblement socialiste à Cuba.

\section{MOTS-CLÉS}

Médicine de famille; génétique; Héritage; cancer du sein; croyance en santé; Cuba.

\section{MEDICINA FAMILIAR, "LA HERENCIA" Y CÁNCER DE MAMA: COMPRENDER LAS (DIS)CONTINUIDADES DE LA GENÉTICA PREDICTIVA EN CUBA}

\section{RESUMEN}

Basándose en la investigación en ciencias sociales que examina la relación entre el conocimiento genético, la identidad y la familia, este documento toma el contexto cultural de Cuba como un lugar de compromiso etnográfico crítico. El artículo se basa en una encuesta a mujeres cubanas y profesionales de la genética como parte de una investigación colaborativa que explora el contexto social y cultural de las creencias de salud sobre el cáncer de seno. Busca iluminar las formas contrastantes en las que se percibe, comunica y desencadena el conocimiento genómico relacionado con un mayor riesgo de cáncer de seno. Se argumenta que la comprensión y 
la importancia particular del riesgo genético relacionado con el cáncer de mama en este contexto deben examinarse en relación con las prácticas institucionales de larga data relacionadas con la prestación de servicios de salud pública. Centrarse en la 'familia' en la política de salud pública cubana proporciona una base particularmente viable para expandir lo que se describe como 'genética comunitaria', incluida la agrupación de detalles del historial de salud familiar para enfermedades complejas comunes como el cáncer de mama. Sin embargo, las percepciones públicas específicas del riesgo relacionado con el cáncer de seno y las dificultades de discutir abiertamente el diagnóstico familiar del cáncer apuntan a desafíos muy específicos en la traducción y aplicación de intervenciones de genética predictiva en Cuba. En resumen, la interrelación dinámica entre la salud pública, las percepciones de riesgo o las creencias de salud sobre las causas de la enfermedad y las actitudes hacia el diagnóstico familiar del cáncer apuntan a continuidades y discontinuidades en la forma en que las intervenciones genómicas del cáncer de seno se están desarrollando como parte de un proyecto de atención de la salud dinámico, pero aparentemente socialista en Cuba.

\section{PALABRAS-CLAVE}

Medicina familiar; Genética; Herencia, cáncer de mama; creencias de salud, Cuba. 


\section{INTRODUÇÃO}

A dinâmicas multifacetadas entre conhecimento genético ou tecnologia e relações familiares vêm sendo atualmente exploradas em uma variedade de maneiras através das ciências sociais. Trabalhos pioneiros que examinam como ideias do senso comum sobre hereditariedade (DAVISON; FRANKEL; DAVEY-SMITH, 1989) e parentesco (RICHARDS, 1996) informam noções de herança genética têm sido ampliados para demonstrar os modos complexos pelos quais família e relações de parentesco estão sendo "colocadas em destaque" (FEATHERSTONE et al., 2006) e, em alguns casos, transformadas por intervenções genômicas. Alguns desses estudos apontam para a o modo como a nova genética está concretizando uma conceitualização "biogenética" de família que desafia diversos grupos de parentes, bem como a ideologia da escolha individual (FINKLER, 2000). Outros destacam as maneiras pelas quais o conhecimento genômico pode ser ligado a novas formas do que vem sendo descrito como biossociabilidade (RABINOW, 1996), dando novos significados a ideias de identidade e relações sociais na família e na comunidade num sentido mais amplo (SILVERMAN, 2008).

Pesquisas anteriores desenvolvidas no Reino Unido sugerem que, especificamente, a área da medicina caracterizada como "genética do câncer de mama" oferece um importante contexto para examinar relações entre identidade, medicina genética e família. Após a identificação de dois genes de predisposição hereditária, ligados ao câncer de mama BRCA1 e BRCA2 - na metade dos anos 1990, houve um crescimento e emergência dessa nova área clínica, cujas práticas tem oferecido um contexto rico para o exame das relações entre genética, parentesco e relações familiares, dentro e fora da clínica. Isso tem revelado a frequentemente contraditória consequência do conhecimento genético para a identidade individual e coletiva. Por um lado, identificou-se uma relação produtiva entre o campo da medicina caracterizado como genética do BRCA (Genética do câncer de mama) e família. Isso tem sido associado a noções de gênero que atribuem à mulher o cuidado (GIBBON, 2007a) ou a ideologias onde a noção de "família tradicional" é constituída por ideias de parentesco biogenético (FINKLER, 2000). Ao mesmo tempo, outras pesquisas também têm revelado uma tensão entre o investimento individual no que é compreendido como saúde preventiva e as consequências relacionais das informações preditivas de risco para a família (GIBBON, 2007b; HALLOWELL, 1999). Como demonstra o trabalho de Konrad, examinando a genética preditiva no contexto da doença de Huntingdon, o conhecimento genético pode ser absorvido de forma desigual na família. Esses estudos ilustram como as relações sociais e pessoais interdependentes entre os parentes podem ser negociadas como "direito de saber" ou "direito de não saber" acerca das informações preditivas sobre riscos (KONRAD, 2005; ver também FEATHERSTONE et al., 2006). 
Estudos de caso têm examinado como podem ser variadas as consequências do conhecimento genético para o contexto das relações na comunidade e família, dependendo da doença e dos significados culturais que estão vinculados a ela. Enquanto Weiner (2010) nota como informações sobre o risco genético pode ter poucas consequências para as relações biossociais para aqueles que tem hipercolesterolemia familiar, Lock (2008) destaca a ausência de novas organizações biossociais em torno da doença de Alzheimer. Ela afirma que isso se dá em parte pelo fato de que há muita dificuldade em criar um regime de cuidado para uma doença incurável e cuja condição é frequentemente debilitante. Como demonstra o trabalho de Rapp (1999), ao examinar um aspecto bastante específico da medicina reprodutiva - a amniocentese - ainda existe muito a ser feito nas sociedades euro-americanas no que diz respeito ao entendimento do que o conhecimento genético e tecnologias estão informando em um contexto variado de família, gênero, religião e etnicidade (ver também SHAW, 2000; 2009). No entanto, estudos antropológicos fora do contexto euro-americano estão demonstrando como diferentes noções de pessoalidade e significados associados com parentesco, família e ou cidadania têm consequências específicas para o significado e o grau de engajamento das informações genéticas. De forma mais ampla, esses estudos apontam para o modo como valores morais situados diferentemente em relação a práticas espirituais, religiosas ou comunitárias e a culturas institucionais, bem como a provisão estatal (ou a falta) de assistência à saúde podem influenciar, facilitar ou impedir a aplicação de novos conhecimentos e tecnologias biológicas (GAMMELTOFT, 2007; GIBBON; NOVAS, 2008; GIBBON; REYNOLDS, 2009; INHORN, 2008; KAMPRIANI, 2009; SLEEBOM-FAULKNER, 2010).

Esse trabalho busca, a partir de uma abordagem crítica, etnográfica e comparativa no contexto cultural específico de Cuba, contribuir para iluminar os limites e variedades da "coprodução" (JASANOFF, 2004; LOCK et al., 2000) na relação entre medicina genética e família. Com um sistema de saúde que há bastante tempo tem se dedicado a oferecer assistência integral à saúde baseada nos princípios de igualdade e universalidade de acesso, Cuba oferece uma arena única para explorar as relações envolvendo medicina genética e a família. Apesar da falta de recursos financeiros e tecnológicos para conduzir uma vasta gama de testes clínicos da genética preditiva para condições como o câncer de mama, há um contínuo comprometimento nesse contexto que mobiliza o que é descrito como "genética comunitária" enquanto um esforço da saúde pública. Em Cuba isso inclui a coleta e análise de dados de histórico familiar associados a doenças complexas como o câncer de mama. Esse trabalho examina as práticas de "genética comunitária" em Cuba, uma vez que se relaciona com um interesse crescente por condições como o câncer de mama e o envolvimento na medicina de família como parte da política estatal de saúde pública. Demonstro como Cuba oferece uma importante arena comparativa para explorar as 
continuidades e diferenças nas relações entre conhecimento genético, pessoalidade, parentesco e família.

\section{MÉTODOS DE PESQUISA}

A análise deste artigo é baseada na pesquisa que faz parte de um projeto colaborativo com equipes de profissionais da genética cubanos em três diferentes províncias - no leste, centro e oeste do país - em diferentes períodos entre os anos de 2006 e 2008. O período de pesquisa mais intenso ocorreu entre setembro de 2007 e março de 2008. Todas as regiões nas quais a pesquisa ocorreu têm uma história particular de desenvolvimento socioeconômico pré e pós revolução. Esses contextos são bastante distintos da capital Havana (ver ROSENDHAL, 1997). Os dados coletados incluem observações etnográficas realizadas durante o acompanhamento de profissionais de saúde cubanos, especializados em genética comunitária, visitando as famílias em suas casas como parte de uma rotina de obtenção da história de saúde familiar, e também o uso de um roteiro semiestruturado de entrevista. Foram entrevistadas 250 cubanas em três diferentes províncias do país. Os assuntos cobertos pela entrevista, que incluía questões abertas e fechadas, focaram nos entendimentos de saúde que dizem respeitos às causas e fatores de risco do câncer de mama, incluindo a genética e o que foi descrito como fatores "não-genéticos". As idades das participantes, todas mulheres, variou entre 16 e 80 anos. Nesse grupo, a metade delas teve no passado ou, em alguns poucos casos, estava tratando o câncer de mama. A amostra e recrutamento dos participantes da pesquisa foi responsabilidade dos colaboradores cubanos da pesquisa. Em contato com policlínicas locais e médicos de família, eles identificaram e convidaram os participantes para fazer parte dessa pesquisa. Nenhuma seleção sistemática de participantes foi feita com base no histórico familiar de câncer de mama. No entanto, aproximadamente um quarto dos participantes dessa pesquisa tiveram pessoas da família afetados com câncer de mama ou outro tipo de câncer. Após o preenchimento do termo de consentimento livre e esclarecido, as entrevistas ocorreram na grande maioria das vezes na casa dos participantes. Profissionais de genética comunitária estiveram presentes durante toda a entrevista e eram responsáveis por preencher e escrever a resposta verbal dos participantes às questões. A pesquisa foi aprovada pelo comitê de ética em pesquisa da Universidade College London em 2006. Os dados qualitativos e quantitativos obtidos pela pesquisa foram analisados de múltiplas formas, utilizando os programas de análise de dados SPSS e ATLAS. Os dados apresentados aqui são parte de ambos os componentes do projeto: dados etnográficos e entrevistas. Isso inclui as respostas de uma série de questões abertas sobre suas percepções e crenças no que diz respeito às causas do câncer de mama; quais fatores de risco eram percebidos como os mais importantes para a doença e sua experiência 
pessoal (quando se aplicava) ou percepção geral acerca do câncer de mama na família e na comunidade. Essas respostas foram analisadas com base em teoria fundamentada em dados, com base em análise de tópicos recorrentes (CORBIN; STRAUSS, 1990), usando o programa ATLAS. Enquanto alguns aspectos dessa pesquisa foram discutidos em outros trabalhos (GIBBON, 2009; GIBBON; KAMPRIANI; ZUR NIEDEN, 2010), outros achados serão publicados como parte de um amplo e diverso produto de dados gerados por essa pesquisa, na medida em que sua análise for concluída.

A primeira metade desse artigo descreve o contexto e emergência do que é descrito como "genética comunitária" enquanto parte de um programa de saúde pública em Cuba. Sugerimos que existe uma significante continuidade entre a assistência integral à saúde pública e a recente expansão da genética comunitária, que se relaciona diretamente com os interesses e o fornecimento do que é descrito como "medicina de família". A segunda parte do artigo se dedica mais diretamente aos dados das entrevistas com as mulheres cubanas ao focar nos significados culturais do câncer de mama e nas crenças associadas com as causas da doença. Isso inclui a percepção de que o câncer de mama é causado por fatores que surgem fora do corpo e o impactam, bem como o significado (ou sua ausência) da genética e o que é entendido como risco hereditário. Essa parte do artigo discute os desafios da prática da genética comunitária considerando as crenças em saúde relacionadas a causas de doenças e também o clima de medo e silêncio na família associado à discussão um diagnóstico de câncer. Os dados apresentados na segunda parte desse artigo mostram que, apesar de uma cultura institucional que tem há muito tempo focado na saúde da família, os pontos de convergência entre a genética comunitária - uma área em expansão - associada à identificação e prevenção dos riscos genéticos do câncer de mama podem não ser tão facilmente alinhados e são, de fato, caracterizados por uma série de descontinuidades, tensões e diferenças.

\section{SAÚDE PÚBLICA, MÉDICOS DE FAMÍLIA E GENÉTICA COMUNITÁRIA}

O desenvolvimento de um sistema integral de saúde pública em Cuba surgiu a partir dos compromissos da revolução no final dos anos 1950. Desde essa época, a saúde pública tem sido tomada como um importante símbolo de sucesso dos esforços da revolução socialista em Cuba (BROTHERTON, 2005; FEINSILVER, 1993). Esse processo de transformação incluiu a criação de serviços locais de atenção primária nos anos 1960 e 1970, com policlínicas localizadas em todo o país, incluindo áreas aonde recursos para a saúde eram parcos ou inexistentes. Junta-se a isso, os milhares de médicos que foram treinados nas décadas que se seguiram. Os dados oficiais do governo sugerem que em 2001 existiam $31 \mathrm{mil}$ médicos e enfermeiros - um para cada 175 pessoas (Ministério Público da Saúde de Cuba - 
MINSAP - 2001). Esse grande aumento de profissionais da saúde, combinado com o foco na saúde materna tem sido tomado como o responsável direto pelo sucesso do sistema de saúde pública cubano - particularmente na redução da mortalidade infantil e no aumento da expectativa de vida (SPIEGEL; YASSI, 2004). Apesar dos desafios econômicos advindos do embargo estado-unidense e do colapso dos subsídios soviéticos em 1990, o perfil epidemiológico do país mudou de "doenças da pobreza para o de doenças do desenvolvimento" - com destaque para doenças cardíacas e câncer. De acordo com o Registro Nacional do Câncer de Cuba, mais de 2000 casos de câncer são diagnosticados anualmente no país, cuja população é de aproximadamente 11 milhões de habitantes. Disso resulta uma incidência de aproximadamente 40 casos a cada 100 mil habitantes (ALVAREZ; GARROTE; TORRES BABIE; GUERRA; JORDAN, 2003). Embora existam variações regionais no país, o câncer de mama é a neoplasia maligna que mais afeta mulheres, e sua incidência - que cresce anualmente - é comparável a uma taxa global (GALÁN et al., 2009).

Muitos autores sugerem que compreender os significados não somente simbólicos da "revolução" na saúde pública em Cuba nos últimos 50 anos, mas também a logística de seu sucesso, pode ser atribuído ao sistema assim chamado de "medicina de família" que que começa a surgir nos anos 1980. O esforço para fornecer mais e mais bem equipados médicos de família que pudessem atender o "bem-estar físico e social" da população cubana foi consolidado pelo estado em 1984 como parte do Programa de Médico e Enfermeiro da Família (MEF) (NAYERI 1995). Esse programa lançou os planos para o atual modelo de atenção à saúde primária, com médicos trabalhando em "consultórios" nas comunidades em que eles viviam. Até 1995 esse sistema foi estabelecido em todo o país e integrou hospitais, serviços de policlínicas locais e médicos comunitários. Isso permitiu a Cuba aplicar e, na perspectiva de alguns autores, em certa medida realizar o princípio de "saúde primária para todos" (SPIEGEL; YASSI, 2004, p. 97). A importância da prevenção e não somente do tratamento foi parte vital desse programa de medicina comunitária, com a saúde sendo vista holisticamente como função do "bem-estar biológico, ambiental e social" (NAYERI, 1995, p. 324). Isso foi muito além da intervenção clínica ao incluir aspectos de "prevenção, instruções de higiene, planejamento familiar e avaliação dos fatores de risco (JENKINS, 2008, p.13 - ver também NAYERI, 1995; BROTHERTON ,2005).

A emergência da "genética comunitária" nos últimos seis anos, enquanto parte de um programa nacional de intervenção, surge diretamente de uma abordagem "holística" e "preventiva" da medicina de família, e de um antigo programa, de quase 40 anos, focado na saúde materna e infantil. Isso se reflete em parte no fato de que muitos profissionais trabalhando atualmente no campo da genética comunitária, tenham atuado anteriormente como médicos de família em suas comunidades, antes de serem treinados como especialistas em genética. Também se reflete na infraestrutura desse novo foco em saúde e no modo 
como ele vem sendo consolidado e associado ao sistema de atenção primária à saúde por meio de programas como o MEF, com redes de centros e clínicas genéticas. Empregando mais de 1600 pessoas em todo o país, muitos centros regionais têm seus próprios especialistas em genética, técnicos e enfermeiros (TERUEL, 2009). Esses centros estão, muitas vezes, alocados nas policlínicas ou hospitais locais, mas quase sempre têm seu próprio prédio, em áreas residenciais com consultórios e laboratórios.

A principal preocupação diária desses centros são os rastreamentos em neonatos para monitorar condições cromossômicas raras e ajudar a facilitar o programa nacional de rastreamento pré-natal para condições como a anemia falciforme. Para fins de comparação, o trabalho de equipes genéticas relacionado a condições complexas de início na vida adulta, como o câncer de mama, está focado na coleta e agrupamento de registros de famílias afetadas por tais condições. Em alguns centros a lista de doenças para as quais os históricos familiares têm sido coletados durante a pesquisa incluem: esquizofrenia, Alzheimer, doenças cardíacas, diabetes e outros tipos de condições comportamentais como o "alcoolismo". Com mais de 43 mil famílias formando parte desse registro nacional, tem-se um recurso muito poderoso para o futuro da pesquisa e medicina genética (TERUEL, 2009). Contudo, devido ao custo e falta de infraestrutura, esses centros ainda não são capazes de fornecer avaliações de risco clínico ou previsões baseadas em testes genéticos para aqueles com histórico de câncer de mama na família. Apesar disso, clínicas de genética comunitária recentemente inauguradas estão envolvidas na tarefa de coletar informações sobre o histórico familiar e identificar as pessoas e famílias com maiores riscos. É importante observar que tal trabalho também foi impulsionado pelo projeto colaborativo que formou a base da pesquisa a partir da qual os dados desse artigo são derivados. Ao mesmo tempo em que esse projeto eга, para os colaboradores cubanos, essencialmente um estudo "exploratório" que ajudaria a avaliar e, talvez no futuro, expandir as práticas de genética comunitária em relação ao câncer de mama, era também um meio de propagar e facilitar o trabalho de coletar informações da história familiar.

Circulando entre comunidades rurais e urbanas com diferentes equipes de médicos geneticistas em três diferentes províncias onde a pesquisa para o projeto estava sendo desenvolvida ficou claro que os geneticistas eram centrais para essas comunidades. Muitos tinham trabalhado por anos como médicos de família, vivendo em ou próximos aos distritos em que eles trabalhavam. Agora, como parte do programa de Genética Comunitária, eles mal podiam caminhar pelas ruas sem encontrar pessoas que conheciam e, mais comumente eram parados por pessoas que os reconheciam. Com frequência comentários bem-humorados eram feitos por eles sobre como suas casas eram como "consultórios" todas as noites para vizinhos, amigos e conhecidos que buscavam conselhos para problemas de saúde. Em uma ocasião, caminhando de volta para a clínica de genética comunitária na área residencial de 
uma pequena cidade de uma província orienta, Celeste, a médica com quem eu estava foi reconhecida e abordada por uma mãe e sua filha adolescente, para discutir o fato de a filha talvez estar grávida e, por consequência, necessitar de um aborto. Ela tinha parado essa médica para perguntar com quem ela deveria conversar na policlínica local sobre esse assunto. Com uma mistura de desânimo e humor seco, Celeste fala sobre ser parada com tanta frequência nas ruas e consultada sobre tais questões. Rindo, ela diz que a genética comunitária na prática "é genética comunitária de verdade!". Essa posição social no coração das comunidades onde esses profissionais viviam era, contudo, particularmente importante com relação ao exame dos detalhes da história familiar, como a experiência em trabalhar com esses profissionais mostrou.

É verdade dizer que o contexto social de crenças e práticas em relação ao câncer de mama - o foco principal de nossa colaboração - também era de algum interesse para esses profissionais de saúde. Eles estavam dispostos a considerar esses aspectos da saúde e bemestar principalmente como resultado de um envolvimento prévio em um amplo sistema baseado no sistema de saúde da família, orientado para uma abordagem preventiva "holística". Contudo, tal envolvimento era também para eles explicitamente sobre a tarefa de registrar os históricos familiares ou identificar famílias de alto risco. Sendo assim, não era surpresa que eles, com frequência, monopolizassem as entrevistas, algumas vezes fazendo desenhos rabiscados de pequenas árvores genealógicas e adicionando outras perguntas sobre datas e detalhes relacionados com o histórico de câncer na família. Diferente da atmosfera tensa que essas questões poderiam gerar no contexto do Reino Unido, logo se tornou evidente que essas eram questões rotineiras e esperadas tanto para os profissionais da saúde quanto para os pacientes em Cuba. A facilidade com que tais informações eram trocadas com médicos era evidente quando acontecia - e esse era frequentemente o caso e de outros membros da família se tornarem parte das discussões na busca pelos detalhes da história da doença. Isso ocorreu uma tarde caminhando em volta de uma residência com dois membros de uma clínica genética local após completar um questionário com uma mulher idosa em um conjunto de casas próximas. Ao encontrar o sobrinho dessa senhora, que o geneticista também conhecia, o médico perguntou sobre o histórico médico de um primo em particular, algo que sua tia não consegui se lembrar. Ele não se surpreendeu ao ser parado na rua, enquanto pedalava de volta para casa, pelo geneticista que conhecia e respondeu com bom-humor e sem hesitação o pedido de esclarecer os detalhes que sua tia havia mencionado sem clareza.

Perguntar e dar informações sobre o histórico familiar é parte da rotina paciente/médico em Cuba, na qual o campo em expansão da "genética comunitária" se debruça. Conforme o exemplo acima demonstra, isso ocorria de forma acentuada em pequenas comunidades, nas quais a relação entre geneticistas e a comunidade егa 
extremamente personalizada. Outro exemplo que ilustra isso diz respeito à frequente preocupação dos profissionais com o fato de os participantes responderem aos questionários com o que consideram as "respostas corretas". De modo semelhante, quando certas questões eram deixadas em branco ou não respondidas pelos participantes, os geneticistas comentavam abertamente preocupados e, ao tentar estimular os participantes, afirmavam, como um desses profissionais: "eles sabem as respostas!".

Os geneticistas cubanos, em sua atenção à saúde da família, ao pré-natal e aos recém-nascidos, são, como outros médicos, símbolos poderosos e incorporados da revolução. O perfil elevado que o programa de "internacionalização", que envolve exportar milhares de médicos para África, Ásia e América do Sul por períodos de um a três anos, tem sido central para essa associação simbólica de médicos com a revolução dentro e fora de Cuba (FEINSILVER, 1993). É importante destacar que nos últimos anos ocorreu a primeira "missão médica" envolvendo profissionais da Genética Comunitária para a Venezuela. Essa identificação de profissionais da genética com a ética socialista e "valores revolucionários", ligada a ideais de equidade e acesso universal de saúde para a população se refletia também nas referências visuais nas próprias clínicas. Murais feitos a mão com mensagens de saúde pública estavam lado-a-lado com poemas de Josi Marti e fotos de "Che", Fidel Castro e Hugo Chávez. Como o projeto colaborativo vinculado à pesquisa se desenvolveu em diferentes províncias, um número significativo de profissionais demonstrou seu comprometimento em trabalhar dessa maneira. Um evento que aconteceu em campo ilustra como esses sentimentos eram manifestados por uma das profissionais de genética comunitária.

Mayra tinha muito orgulho em me mostrar o novo prédio, recentemente construído, da clínica de genética comunitária da qual ela era gerente. Diferente dos edifícios velhos e com pouca manutenção, o centro de genética comunitária se destaca com um edifício reluzente no alto de uma colina, com vista para uma cidade em uma das províncias do leste do país. Sua localização próxima de uma maternidade, em parte, reflete o modo como a Genética Comunitária Cubana se desenvolve e amplia seu sucesso para a saúde maternoinfantil. Dentro do novo centro, acessórios e novos equipamentos revelam que ainda há trabalho para completar o centro. Esse é também um dos poucos prédios com arcondicionado na cidade. Ao caminharmos pela sala de conferências recentemente pintada, que será usada para as reuniões regionais de profissionais da genética comunitária, a conversa migra para como Mayra se tornou diretora da clínica regional nessa pequena cidade. Ela fala sobre um período em que ela foi médica de família em Sierra Maestra e das dificuldades do chamado "Período Especial", que seguiu o colapso dos subsídios soviéticos no final dos anos 1980, e como isso inspirou seu trabalho. Desde então, ela sempre quis poder voltar para a cidade na qual ela cresceu e trabalhou. Após ser treinada em genética, ela teve a oportunidade de estabelecer os serviços de genética comunitária na sua cidade 
natal. A dedicação de Mayra ao trabalho é percebida pelos demais trabalhadores do centro. Uma enfermeira, fazendo algumas observações engraçadas e afiadas havia dito em um tom um pouco irônico que, diferente dos "outros médicos" que deixaram cuba, Mayra era uma "boa comunista". Mayra falou sobre como quer colocar plantas do lado de fora do prédio para tornar a área mais confortável e receptiva para os pacientes. Ela também mencionou que haverá uma escultura na frente do prédio, e me levou até uma pequena sala aonde ela está sendo guardada. É uma representação clássica da dupla hélice de DNA. Mas ela me diz que não irão usar essa escultura, pois é "muito feia". A escultura que será colocada na frente do edifício é algo mais abstrato e orgânica, diferente da óbvia representação do DNA ou do conhecimento científico. A escolha da escultura pública, na entrada no novo edifício da genética comunitária parece refletir simbolicamente o esforço em representar e posicionar o trabalho do geneticista médico como parte de um amplo projeto de saúde comunitária pública. Trata-se de afirmar um aspecto da saúde pública cubana, construída a partir de um amplo e duradouro programa de saúde pública ao invés de fazer algo novo ou diferente.

Investimentos de longa data e organização na saúde pública em Cuba têm colocado o local e o comunitário como foco da medicina de família e, este último como o coração e alma, a partir do qual a genética comunitária parte e se constrói. Essa situação parece prover um certo grau de vantagem para o crescimento e expansão da medicina genética em cuba, incluindo aquela que tem relação com a genética do BRCA. Como o material etnográfico delineado acima sugere, médicos de família e profissionais da genética comunitária são componentes vitais desse empreendimento, situado no coração de um sistema de saúde organizado localmente e centrado na família. Ao mesmo tempo, seu comprometimento em integrar a genética comunitária no projeto cubano de saúde pública, que nem sempre é acrítico ou desconhecedor dos desafios e recursos dispendidos para realizar esse propósito em Cuba (ver GIBBON, 2009) - é, no entanto, central para o sucesso e expansão desse campo da medicina. Na próxima sessão desse artigo irei abordar questões que emergiram a partir das entrevistas respondidas por mulheres cubanas. Ao focar nesses dados, relacionados com as crenças dos participantes sobre saúde, suas preocupações sobre herança e riscos genéticos, examino as diversas e, muitas vezes, desiguais formas pelas quais a cultura institucional da medicina de família e da genética comunitária informam os significados da genética do câncer de mama em Cuba. A cultura institucional local da saúde pública cubana, vista na primeira parte desse artigo, parece prover um contexto fértil para a contínua expansão da genética comunitária enquanto medicina de "família". No entanto, alguns dados das entrevistas, relacionados as crenças em saúde e dificuldades de falar sobre o câncer na família colocam alguns desafios para a implementação de intervenções de saúde preditivas ligadas ao câncer de mama no contexto cubano. 


\section{COMPREENDENDO O SIGNIFICADO E A MORALIDADE EM TORNO DO RISCO DE CÂNCER DE MAMA: HISTÓRIA FAMILIAR, "LA HERENCIA" E "LOS GOLPES"}

A análise de certos aspectos dos dados das entrevistas com mulheres cubanas relacionadas as questões abertas relativas a crenças sobre as causas do câncer de mama, fatores de risco e experiência da doença (quando relevante), apontam para a importância de uma gama de percepções. Em contraste com pesquisa semelhante realizada no Reino Unido (ver por exemplo, GIBBON, 2007a), o significado do "risco de câncer de mama", bem como a moralidade associada a "preocupações com a saúde" e o envolvimento em intervenções preventivas pareciam ser articuladas de modo diferente (ver também, GIBBON, 2009; GIBBON et al., 2010) para uma discussão aprofundada desse contraste). Aqui, dois aspectos específicos das crenças em saúde das mulheres cubanas sobre as causas do câncer de mama serão examinados. O primeiro diz respeito ao modo como os fatores genéticos e hereditários são entendidos e discutidos. O segundo tem relação com a maneira pela qual o que foi descrito como "uma pancada" é visto como a causa primária da doença. Eu argumento que esse é um modo ilustrativo de descrever o risco de desenvolver a doença, visto na maioria das vezes como um processo no qual a doença surge e impacta o corpo ou como o resultado de ações individuais (ou omissões). Em outro trabalho eu explorei os achados em relação a outros dados como a importância de fatores alimentares e o significado do "estresse" (GIBBON et al., 2010).

Dada a relativa indisponibilidade dos testes de genética preditiva em Cuba, a ausência de exageros e discussões esperançosas sobre os genes "BRCA" na mídia, bem como a ausência de uma forte cultura ativista sobre o câncer de mama (certamente fora de Havana), não foi surpreendente descobrir que poucas das mulheres que completaram o questionário tinham ouvido falar sobre os genes "BRCA". Talvez ainda mais surpreendente foi o fato de que muitas não tinham referência alguma sobre os termos "genes" ou fatores "genéticos". Muitas vezes encontrávamos olhares de perplexidade e dúvida em resposta a perguntas abertas sobre se elas sabiam algo sobre "los genes" ou "la genetica". Para aquelas poucas pessoas que o termo "genes" era significativo, a discussão se centrava em uma vaga noção de algo transmitido pelo sangue. Este era o modo como certo número de pessoas expressavam isso;

"Penso que é algo que se transmite de uma família a outra pelo sangue".

"Os genes são algo no sangue que dão a herança e para o câncer também".

\footnotetext{
${ }^{4}$ N.T. Traduzimos a palavra 'golpe' por 'pancada', pois este é o termo recorrentemente usado em português, por mulheres brasileiras, para se referir ao surgimento de tumores nos seios, em acepção muito próxima àquela observada pela autora em Cuba.
} 
Foi significativo que quando questões semelhantes sobre risco genético foram reelaboradas em termos de "fatores hereditários" houve um reconhecimento positivo mais amplo. Isso quer dizer que muito havia mais probabilidade de discussão e compreensão de que "la herencia" e "la salud o las enfermidades" dos "antecedentes" ou "antepassados" poderiam contribuir para o risco da doença. Isso sugere que existia uma saliência cultural no contexto em torno do risco hereditário, e não nos genes, fatores genéticos ou mais especificamente nos genes BRCA.

Isso ficava evidente no modo como questões relacionadas a genes, em oposição a fatores de risco hereditários, poderia revelar respostas negativas e positivas da mesma pessoa. Isso foi sutilmente ilustrado pelos comentários desta entrevistada. Ao falar sobre como ela soube sobre a relação entre fatores hereditários e o câncer de mama, ela disse:

"em documentários da televisão, em conversas com pessoas se fala que é um fator importante porque há várias pessoas na família que são afetadas. De como é que os genes produzem o câncer, não tenho escutado".

Outra mulher foi mais cautelosa em sua resposta:

"poderia ser uma causa genética, não escutei em especifico sobre os genes em relação ao câncer de mama".

Outras pessoas foram mais diretas em demonstrar sua incredulidade diante da afirmação de que o câncer de mama era ligado a hereditariedade ou a fatores genéticos - "a herança não está vinculada com o câncer de mama". Em outro exemplo, duas irmãs que tiveram ambas câncer de mama falaram sobre suas experiências compartilhadas de viver o tratamento. Uma delas disse: "somos gêmeas em relação ao câncer de mama". Apesar disso, elas negaram a sugestão da existência de alguma relação de hereditariedade no fato de ambas terem tido câncer de mama.

Uma mulher, em resposta a uma questão sobre os genes ligados ao câncer de mama, fez uma distinção clara entre fatores genéticos desconhecidos e risco hereditário conhecido:

"Não tenho conhecimento disso [fatores genéticos], mas penso que pode ser hereditário ou pode ser que a pessoa nasça com isso e se manifeste em qualquer idade"

Enquanto os "genes BRCA" e fatores genéticos não são uma referência para muitos participantes, o risco hereditário o é, como demonstram esses exemplos em que o risco é associado ao aumento de incidência de câncer de mama. Enquanto algumas entrevistadas achavam que fatores como ter um histórico familiar poderia ser importante para o desenvolvimento de câncer de mama especificamente, não havia nenhuma referência ao câncer de mama enquanto uma doença "genética" - objeto de anúncios amplamente divulgados, em meados dos anos 1990 no Reino Unido e outras sociedades euro-americanas, que informavam, cheios de esperança, a descoberta e a aplicação de novos conhecimentos 
sobre os genes BRCA (GIBBON, 2007a; PARATHASARATHY,2007). Também não era insignificante notar que ao responder as questões, doenças como diabetes e asma eram muito mais rápida e facilmente ligadas a fatores hereditários do que o câncer de mama. Ambas as doenças citadas são atendidas diretamente através do programa de medicina de família. Em resumo, a disjunção entre o que era percebido como fatores hereditários mais significativos e o que pode ser descrito como fatores genéticos desconhecidos, sugere que o primeiro tinha uma ressonância importante na vida das pessoas, enquanto o último não.

Essa situação pode ser lida de muitas maneiras em relação a cultura institucional e valores ideológicos transmitidos através do projeto cubano de saúde pública e sistema de medicina de família que está posto em prática nos últimos 20 anos. Isso assegura, no mínimo, que prestar atenção à história da doença na família é usual. Como uma das entrevistadas respondeu à uma pergunta sobre por que ela acreditava que os fatores hereditários eram importantes para o câncer de mama, dizendo: "porque nas consultas sempre perguntam se tem antecedentes familiares com enfermidades". Esse aspecto foi mais sucinta e diretamente interpretado por um geneticista que disse: "as pessoas estão acostumadas às questões sobre o histórico de saúde familiar ou acreditam que isso é importante porque nós sempre perguntamos sobre isso".

É notável que ao responder a questões diretas sobre a história familiar aos geneticistas muitas pessoas falavam com muita disposição essas informações. Mais ainda, muitos sabiam detalhes precisos do histórico médico da família, lembrando não somente de datas em que algum parente havia morrido ou recebido um certo diagnóstico, mas algumas vezes sabiam detalhes dos procedimentos médicos aos quais eles ou um parente havia sido submetido. Em outro trabalho argumentei que essa habilidade impressionante de conhecer e narrar a história médica da família ou estar envolvido com procedimentos, histórias, e cenários biomédico, que frequentemente constituem uma resposta a questões sobre a experiência do câncer de mama, revela em que medida a cidadania biologizada pode estar em jogo na arena cubana (GIBBON,2009).

Ainda assim, ao examinar mais detalhadamente o modo pelo qual o "risco corporificado" associado ao câncer de mama é compreendido por mulheres cubanas nos dá um outro contexto para entender os desafios e descontinuidades na tradução das intervenções da saúde preditiva relacionada ao câncer de mama no contexto cubano.

É possível afirmar que existem algumas discussões levantadas por algumas entrevistas que dizem respeito à necessidade do autocuidado, e que negligenciá-lo eгa percebido com como prejudicial ao bem-estar e poderia levar à doença. Isso estava mais presente para as participantes que viviam ou trabalhavam em áreas mais turísticas ou por aquelas que tinham família vivendo fora do país, com acesso, ainda que limitado, a recursos financeiros extras. Todavia, o discurso moral sobre a responsabilidade individual pela saúde, 
sugerida como central por outras pesquisas no Reino Unido e por mobilizações de pacientes em torno da "genética do BRCA" (ver GIBBON, 2007a), era um terreno de discussão distante do óbvio para a maior parte daqueles que participaram dessa pesquisa.

Por exemplo, os chamados "fatores de risco associados ao estilo de vida", embora reconhecidos como importantes para a saúde de maneira geral, nem sempre eram vistos como fatores que os próprios indivíduos poderiam facilmente modificar ou gerenciar. De maneira geral, existia um sentimento que o maior risco vinha de fora e seu impacto se dava sobre o corpo. Conforme argumentei em outro trabalho, isso significa identificar fatores de risco que estão não somente fora do controle dos indivíduos, mas, algumas vezes, fora do controle do Estado cubano. Isso pode incluir a poluição causada por conflitos internacionais no Iraque ou Afeganistão, contaminação ambiental, e destruição da camada de ozônio (GIBBON, 2009) ou um "déficit" nutricional (GIBBON et al., 2010). Aqui eu exploro essa representação da corporeidade em relação a percepção de risco relacionada ao câncer de mama ao examinar a frequência e a maneira através da qual as entrevistadas explicam as causas da doença a partir "uma pancada".

É notável que ao responder perguntas sobre as causas ou fatores de risco, mais da metade do total de entrevistadas acreditava que foi um "golpe" a causa primária ou secundária, ou um fator do desenvolvimento do câncer. Enquanto essas descrições eram algumas vezes intercambiáveis em referência a golpes físicos ou psicológicos ${ }^{5}$ que podem ter causado a doença, elas eram o significado formal mais evidente para as participantes.

Para alguns a simples referência a uma "pancada" era suficiente para "desencadear" o câncer: "uma pancada pode causar câncer de mama". Para outras, a pancada pode estar relacionada a fatores hereditários de modo mais explícito. Por exemplo, isso poderia ser usado para enfatizar as causas do câncer: "não se relaciona com a hereditariedade, se relaciona com uma pancada que recebeu". Em outras vezes essa racionalização era inversa, mas sempre servia para enfatizar a importância da "pancada" para entender a causa do câncer de mama:

"pensa que o mais importante é o fator hereditário, porque nem todos em sua família sofreram pancadas"

Para algumas o fato de um golpe físico que não pode ser tratado em tempo ега percebido como o problema. Como uma mulher disse: "as pancadas que não se cuidam bem podem originar um coagulo e daí um câncer". Esse tipo de afirmação revela o grau de importância que o autocuidado tem, assegurando que cuidados médicos precisam ser buscados. Isso sugere também que, pelo menos para alguns indivíduos, a preocupação com a saúde não era ausente dentro desse tipo de raciocínio.

\footnotetext{
${ }^{5}$ O trauma psicológico era descrito como golpe e algumas vezes era descrito como a própria experiência de ter câncer.
} 
É também importante notar que ideias acerca gênero feminino eram algumas vezes parte da discussão sobre o modo como a "pancada" na mama era percebido como fator de risco para o câncer de mama. Eram feitas menções frequentes aos seios como "uma zona delicada para as mulheres", suscetível a machucados. Também se falava sobre como atividades inapropriadas para mulheres, ou o que era descrito como "força física" também era implicado no desenvolvimento de câncer. Na opinião de alguns isso poderia estar ligada ao novo fato de mulheres precisarem fazer trabalhos mais pesados devido a demandas econômicas seguindo o "período especial", ou pode se referir ao recente envolvimento de mulheres em esportes tradicionalmente masculinos, como boxe ou musculação. Essas percepções parecem refletir, em parte, ansiedades sobre mudanças no papel das mulheres na sociedade cubana. Ilustrou esse sentimento o comentário de uma participante que acreditava que os golpes que ela recebeu de um rifle, durante a luta pré-revolucionária, da qual ela fez parte no final dos anos 1950, causaram seu câncer: "o mais importante creio que é uma pancada, eu recebi pancadas quando estava na clandestinidade, me golpearam com um fuzil".

Outros pesquisadores, trabalhando nos Estados Unidos ou no México notaram que a "pancada" não é uma explicação rara para o câncer de mama, especialmente entre hispânicos (mas há ocorrências também entre populações não hispânicas) (FINKLER, 1991). Hunt afirma que, em seu trabalho no México, o "golpe" pode funcionar como uma noção de "stress" no ocidente, provendo uma "ponte conceitual" e uma forma de "raciocínio moral" entre a desordem no corpo e na sociedade, do mesmo modo que a noção de "stress" fornece "um símbolo flexível e versátil, localizando a fonte da desordem dentro da história do indivíduo". Mas como Hunt também reconhece, é importante também localizar o fator de risco em termos de um "ataque de fora" (minha ênfase, HUNT, 1998 p.304). Isso sugere algo levemente diferente de certas leituras "ocidentais" de stress que normalmente se centrariam na culpabilidade do indivíduo.

A frequência do recurso explicativo sobre os casos de câncer de mama ou o risco de desenvolver a doença como algo ligado a uma "pancada" fornece uma ilustração do modo como, para muitas mulheres cubanas, os agentes etiológicos causadores da doença mais importantes são aqueles que impactam na pessoa, corpo ou personalidade, ao invés de serem gerados de dentro do corpo ou que surgiram como o resultado das ações do próprio indivíduo. Tais leituras parecem refletir a percepção do câncer não como um produto do "corpo lutando contra si mesmo", algo comum em leituras ocidentais sobre o câncer, (SONTAG, 1991; STACEY, 1997) mas estando sobre ataque, ou como resultado de ações de agentes externos "impessoais". Isso pode ser compreendido em relação ao contexto de escassez econômica em Cuba, que começou com o que é comumente chamado de Período Especial, após o colapso dos subsídios soviéticos nos anos 1990. Alguns autores sugerem que 
esse clima de carência ajudou a fomentar a cultura capitalista necessária em práticas de trocas e permutas (Brotherton, 2005, 2008). Os dados qualitativos apresentados aqui relacionando as crenças sobre o câncer de mama, entre as participantes de fora da metrópole Havana, sugerem que esse clima também informou percepções corporificadas de "futuros riscos" de maneiras que não fornecem necessariamente um contexto viável para a expansão da genética preditiva.

Um recente e proeminente discurso dentro das ciências sociais, que surgiu parcialmente em resposta aos modos de entender e significar a identidade no contexto da genômica, tem sugerido e afirmado que existe uma conexão ideológica forte entre o surgimento de conhecimento genético e a expansão do que tem sido descrito como "auto atualização" da pessoa. Em outras palavras, a ideia de que existe uma obrigação moral em responsabilizar o próprio indivíduo por sua saúde é algo como um pré-requisito, e também uma consequência, de novas tecnologias biomédicas e medicina genômica (ver ROSE; NOVAS, 2005). Trata-se de uma forma particular de "cidadania biológica" ligada à florescente cultura do ativismo do câncer de mama, que mobiliza uma ideologia de saúde preventiva na sua ênfase em vigilância e na preocupação individual, e que parece ter sido um importante aspecto para o crescimento e expansão da genética do câncer de mama no Reino Unido e nos Estados Unidos (GIBBON, 2007a,b; PARATHASARATHY, 2007). Também há evidências de que a ênfase na conscientização da saúde feminina é mais complexa, e um importante fator no modo como esse campo da medicina tem se ampliado em outros países, como Kampriani (2009) demonstra em seu trabalho sobre a Grécia. Em Cuba tal ativismo em saúde coletivo ou individualizado, no que diz respeito ao câncer de mama, parece ausente e diferentemente configurado. Isso se deve ao fato de que não somente as ações individuais não são percebidas como a causa primária das doenças como o câncer, mas que os agentes mais perigosos estão localizados fora do corpo. Isso não quer dizer que a noção de responsabilidade individual esteja totalmente ausente no discurso de saúde pública cubano, que, por sua vez, tem respondido dinamicamente às mudanças no contexto político e o ambiente de assistência à saúde (ver BROTHERTON, 2005). Houve exemplos, como mencionado anteriormente, ao realizar entrevistas em certas partes do país, mais próximas da metrópole Havana ou regiões turísticas aonde a evidência de um discurso de cuidados com a saúde informava as respostas das participantes em questões sobre risco (GIBBON et al., 2010). Apesar dessa preocupação e do interesse em "fatores hereditários", diferenças críticas no modo como o risco corporificado era configurado pelas mulheres cubanas que responderam a essa pesquisa sugere que existe um contexto em que os requisitos aparentes para a expansão da genética preditiva são menos acessíveis e visíveis.

A última seção desse artigo busca aprofundar esse aspecto ao lidar com uma das dificuldades enfrentadas pelos profissionais da genética ao circularem em suas comunidades 
locais coletando a história familiar sobre uma doença que é temida e estigmatizada como o câncer.

\section{DA GENÉTICA COMUNITÁRIA À GENÉTICA PREDITIVA: OS DESAFIOS DE FALAR SOBRE 0 "CÂNCER" NA FAMÍLIA}

Apesar da consolidada cultura institucional de saúde da família, que parece prover um ponto de partida lógico para a expansão da genética comunitária em Cuba para incluir as intervenções preditivas, a leitura da do "risco de câncer de mama" pelas cubanas que entrevistamos sugere que essa transição não é tão facilmente alcançada. O trabalho de pesquisa etnográfica junto dos profissionais de saúde, destacou uma questão que se tornou evidente ao longo da aplicação das entrevistas com as famílias nas suas casas. Trata-se do desafio de falar abertamente sobre o diagnóstico de câncer na família. Dada a troca fácil de informações sobre o histórico de saúde familiar que a prática e a cultura da genética comunitária e saúde da família parece facilitar em Cuba, essa dificuldade parece contraditória. Ela reflete o terror e o medo que em Cuba é associado a doenças modernas como o câncer e a cultura paternalista que afeta as práticas de saúde pública.

A habilidade dos profissionais da saúde de acessar e, por sua vez, o modo como os pacientes fornecem voluntariamente suas informações sobre o histórico de saúde familiar e outras doenças é um aspecto fundamental do desenvolvimento de intervenções da genética preditiva. Até mesmo no contexto euro-americano, no qual a possibilidade de testar doenças genéticas é mais amplamente acessível, obter informações sobre o histórico familiar ainda é de suma importância para procedimentos de avaliação de risco, nas decisões sobre fazer ou não testes e na ajuda a estabelecer o significado de mutações e testes preditivos (GUTTMACHER et al., 2004). A necessidade de um engajamento coletivo familiar na medicina genética preditiva é evidente quando o requisito de compartilhar e repassar informações sobre risco para a família se perde, impedindo e algumas vezes até obstaculizando a busca de um diagnóstico de risco genético para diferentes membros da família (GIBBON, 2007b; HALLOWELL, 1999; KONRAD, 2005). Apesar do fato da cultura institucional da medicina de família em Cuba parecer facilitar a coleta da história familiar e, potencialmente, a expansão dessa área da medicina preditiva no futuro, a impossibilidade de discutir e partilhar o diagnóstico entre um paciente e sua família representa um desafio prático e ético para a genética comunitária em Cuba. Enquanto o histórico de procedimentos médicos e intervenções hospitalares podia ser amplamente conhecido e rememorado pelos pacientes e suas famílias, o diagnóstico de câncer, especificamente, algumas vezes era expresso em termos metafóricos ou simplesmente ausente das conversas individuais e coletivas. 
Isso foi ilustrado em uma série de ocasiões durante o trabalho com os profissionais de saúde cubanos. Nessas ocasiões, ao chegar na casa de uma participante da pesquisa, poderíamos ser recebidos por um parente ansioso. Ao mesmo tempo em que eles se demonstravam muito contentes em receber as perguntas para entregar a participante, eles estavam preocupados em como a parente (normalmente nessas situações, as parentes eram a mãe, avós e tias) descobriria que tem ou já tiveram no passado câncer ou "el cangrejo"(o caranguejo - como a doença era metaforicamente descrita). Algumas vezes essa dificuldade levava à decisão de não receber o questionário. Em outros momentos, quando era pouco claro se o parente havia tido ou tem câncer, as questões eram reformuladas pelo profissional de genética comunitária para evitar o uso da palavra "câncer". Nessas situações, "problemas com las mamas", "nódulos" ou outros eufemismos seriam utilizados alternadamente pelos geneticistas, parentes e até mesmo pelas entrevistadas ao responder as questões. Recentes trabalhos em Cuba sugerem que a tradição em não revelar o diagnóstico para os pacientes (ROLL; SIMMS; HARDING, 2009), reflete um consolidado paternalismo no sistema de saúde pública. Isso, associado com a dinâmica de cuidado dentro da família que assume que não revelar para o parente seu diagnóstico de câncer é a melhor ação a ser tomada, constitui uma série de desafios problemáticos para os geneticistas para levar adiante muitos aspectos de seu trabalho. Isso inclui os preceitos e guias que dizem respeito à ética relacionadas ao consentimento livre e informado individual (GIBBON, 2009). A incapacidade de garantir testes preditivos de abrangência garante, em parte, que a partilha de informações sobre riscos genéticos entre familiares não se constitua ainda em um desafio em Cuba. Apesar disso, os problemas relacionados à discussão do diagnóstico de câncer com e entre o paciente e sua família, refletem um ponto significativo de ruptura e descontinuidade na tradução da medicina preditiva para o contexto cubano.

\section{CONCLUSÃO}

Este artigo, escrito a partir do trabalho de campo conduzido com um grupo de mulheres cubanas e trabalhando com profissionais da genética médica explorou algumas das desigualdades e disjunções que caracterizam a tradução da medicina genética associada ao câncer de mama pra um contexto nacional/cultural muito específico. Tem-se defendido que é preciso situar as continuidades e descontinuidades que caracterizam esse em sua relação com um conjunto de práticas sociais e discursos culturais que possibilitam e, ao mesmo tempo, desafiam esse esforço de diferentes maneiras. Isso inclui a consolidada cultura institucional de saúde pública cubana, percepções e crenças das participantes acerca dos riscos relativos ao câncer de mama e o desafio de falar abertamente sobre o diagnóstico de câncer entre pacientes ou com os profissionais de saúde no contexto da família. 
De certo modo, o caso cubano parece indicar a presença de continuidades na prática e oferta de saúde pública e as novas intervenções relacionadas à avaliação de risco genético em doenças difundidas e complexas, como é o caso do câncer de mama. A etnografia sugere que aspectos consolidados do sistema de saúde - aspectos esses organizados localmente e com foco na saúde da família - têm ajudado a dar sentido e importância à ideia da história familiar enquanto um fator de risco para a doença, ao passo que também impulsiona o emergente campo médico da genética comunitária. Nisso, pois, consiste o trabalho de coleta da história familiar e manejo de relações interfamiliares delicadas que fazem parte da intervenção genética e são centrais para o cuidado tácito dentro da comunidade. Aqui, os médicos operam como guardiões paternos e ponte de acesso a essa e outras informações de saúde. Mesmo sem recursos financeiros ou tecnológicos para realizar testes preditivos de maneira mais ampla, estar em condições de estabelecer a ligação entre dados genealógicos e informações clínicas confere maior escopo e flexibilidade para o exercício da medicina genética em Cuba, um campo em plenos surgimento e transformação.

A segunda parte deste artigo destaca como alinhamentos entre o foco na medicina de família e medidas tomadas para incorporar as intervenções da saúde preditiva em Cuba estão de fato imersos em dificuldades e tensões que impedem uma tradução simples da genética do "BRCA" nesse contexto. Esses três aspectos da dinâmica foram aqui. A partir da análise de dados qualitativos acerca das crenças relacionadas ao câncer de mama, os dados apresentados aqui sugerem que, se, por um lado, o histórico de saúde da família é percebido como um fator de risco para uma série de doenças (não apenas o câncer), para várias participantes da pesquisa, falar em termos de "risco genético" acabava não dizendo muito. Ao mesmo tempo, certas percepções de risco se apoiam não tanto em um discurso sobre a responsabilidade moral do indivíduo, e sim em um entendimento de que o mais provável risco de câncer é introduzido por agentes cancerígenos externos a, ou que operam sobre o indivíduo. Este artigo mostra exemplos dessa percepção de que há golpes físicos dirigidos contra os seios e pressuposições relativas a gênero acerca de atividades excessivas do que se compreende como atividades "não naturais" realizadas por mulheres. Se, por um lado, uma análise mais aprofundada desse amplo e diverso conjunto de dados poderá melhor iluminar esses achados, por outro lado, os dados aqui apresentados salientam a necessidade de examinar as várias identidades biossociais em jogo na tradução de tecnologias genômicas para um contexto nacional e transnacional global diverso (GIBBON et al.,2010). A última seção desse artigo aponta ainda para outra dificuldade associada aos esforços de incorporar a medicina preditiva que, de alguma forma, entra em conflito e parece estar em desacordo com a cultura institucional da medicina de família em Cuba. Aqui os silêncios e o uso de linguagem metafórica que podem caracterizar os discursos familiares e médicos relacionados 
ao diagnóstico de câncer constituem um notável desafio ético e logístico para a tradução de intervenções preditivas ligadas ao aumento do risco de doenças como o câncer de mama.

Em resumo, a configuração muito particular de fatores geradores do contexto dentro do qual surge a genética do câncer de mama em Cuba, exemplifica de maneira contundente a necessidade de perspectivas comparativas mais amplas quando se trata de examinar a relação entre intervenções genéticas e a família. Os dados apresentados aqui demonstram a importância de examinar comparativamente o modo como variáveis cultural e historicamente específicas precisam ser contabilizadas na medida em que o trabalho de tradução da medicina preditiva é conduzido em diferentes contextos nacionais. Isso inclui compreender as continuidades, disjunções e diferenças em jogo na relação dinâmica entre medicina genética, identidade e família.

\section{AGRADECIMENTOS}

O financiamento para a pesquisa aqui apresentada foi concedido pelo Welcome Trust, por intermédio de um post-doctoral fellowship award número WT068432M. Minha sincera gratidão a todas as participantes cubanas desta pesquisa e àquelas que possibilitaram sua conclusão. Também sou grata aos pareceristas anônimos cujos comentários foram inestimáveis para a redação das primeiras versões deste artigo.

Texto traduzido por Débora Allebrandt, Felipe Benedet Maureira; Roberta Reis Grudzinski e Waleska Aureliano

\section{REFERÊNCIAS}

ALVAREZ, Y. G.; GARROTE, L. F.; TORRES BABIE, P.; GUERRA, M.; JORDAN, M. G. Breast cancer risk in Cuba. MEDICC Review, n. 5, p. 2-3, 2003.

BROTHERSON, S. Macroeconomic change and the biopolitics of health. Journal of Latin American Anthropology, v. 10, n. 2, p. 339-369, 2005.

BROTHERSON, S. "We have to think like capitalists but continue being socialists": medicalised subjectivities, emergent capital and socialist entrepreneurs in post-soviet Cuba. American Ethnologist, v. 35, n. 2, p. 259-274, 2008.

CORBIN, J.; STRAUSS, A. Grounded theory research: procedures, canons, and evaluative criteria. Qualitative Sociology, n. 13, p. 3-21, 1990.

DAVISON, C.; Frankel, S.; DAVEY-SMITH, G. Inheriting heart trouble: the relevance of common-sense ideas to preventive measures. Health Education Research Theory \& Practice, v. 4, n. 3, p. 329-340, 1989. 
FEATHERSTONE, K.; ATKINSON, P.; BHARADWAJ, A.; CLARKE, A. (Org.). Risky relations: Family and kinship in the era of new genetics. London: Berg, 2006.

FEINSILVER, J. Healing the masses: Cuban politics at home and abroad. Berkely: University of California Press, 1993.

FINKLER, K. Physicians at work, patients in pain. Biomedical practice and patients response. Boulder: Westview Press, 1991.

FINKLER, K. Experiencing the new genetics: Family and kinship on the medical frontier. Pennsylvania: University of Pennsylvania Press, 2000.

GALÁN, Y.; FERNÁNDEZ, L.; TORRES, P.; GARCÍA, M. Trends in Cuba'scancer incidence (1990 to 2003) and mortality (1990 to 2007). MEDDIC Review, v. 11, n. 3, p. 19-26, 2009.

GAMMELTOFT, T. Prenatal diagnosis in postwar Vietnam: power, subjectivity, and citizenship. American Anthropologist, n. 109, p. 153-163, 2007.

GIBBON, S. Genomics as public health? Community genetics and the challenge of personalised medicine in Cuba. Anthropology and Medicine Special Issue: Biomedical Technology and Health Inequities in the Global North and South August, v. 16, n. 2, p. 131-147, 2009.

GIBBON, S. Breast cancer genes and the gendering of knowledge; science andcitizenship in the cultural context of the 'New Genetics'. London, Basingstoke: Palgrave Macmillan, 2007a.

GIBBON, S. (2007b). Genealogical hybridities; the making and unmaking of bloodrelatives and predictive knowledge in breast cancer genetics. In J. Edwards, S. Gibbon, P. Wade, \& P. Harvey (Eds.), Ways of knowing; epistemologies in practice. Oxford: Berg.

GIBBON, S.; KAMPRIANI, E.; ZUR NIEDEN, A.. 'BRCA Patients in Cuba, Greece and Germany: comparative perspectives on public health, the state and the partial reproduction of 'neo-liberal' subjects'. BioSocieties, n.5, p. $440-466,2010$.

GIBBON, S.; NOVAS, C. (Org.). Biosocialities, genomcs and the social sciences; making biologies and identities. London: Routledge, 2008.

GIBBON, S.; REYNOLDS, S.. Introduction. In S. Gibbon, \& S. Reynolds (Eds.), Biomedical technology and health inequities in the global north and south. Anthropology and Medicine Special Issue, v.16, n. 2, p. 131e147, 2009.

HALLOWELL, N. (1999). Doing the right thing: genetic risk and responsibility. In J. Gabe \& P. Conrad (Eds.), Sociology of health\&illness monograph 5: Sociological perspectives on the new genetics. Sociology of Health \& Illness, v. 21, p. 597-621, 1999.

HUNT, L. Moral reasoning and the meaning of cancer: causal explanations of oncologists and patients in southern Mexico. Medical Anthropology Quarterly, v.12, n. 3, p. 298-318, 1998.

INHORN, M. Reproductive disruptions: Gender, technology and biopolitics in the new millenium. Berghahm books, 2008.

JASANOFF, S. States of knowledge: the co-production of science and the social order. London: Routledge, 2004.

JENKINS, T. Patients, practitioners and paradoxes: responses to the Cuban health crisis of the 1990's. Qualitative Health Research, v. 18, n. 10, p. 1-17, 2008. 
KAMPRIANI, E. Between religious philanthropy and individualized medicine: situating inherited breast cancer risk in Greece. Anthropology and Medicine Special Issue: Biomedical Technology and Health Inequities in the Global North and South, v. 16, n. 2, p. 147-165, 2009.

KONRAD, M. Narrating the new predictive genetics. Cambridge: Cambridge University Press, 2005.

LOCK, M. Biosociality and susceptibility genes: a cautionary tale. In: S. Gibbon, \& C. Novas (Org.), Biosocialities, identity and the social sciences; making biologies and identity. London: Routledge, 2008.

LOCK, M.; YOUNG, A.; CAMBROSIO, A. (Org.). Living and working with the new medical technologies: Intersections of inquiry. Cambridge: Cambridge University Press, 2000.

Ministerio de Salud Publica (MINSAP). Republica de Cuba. La Habana, Cuba: Annuario Estatístico, 2001.

NAYERI, K. The Cuban health care system and factors currently undermining it. Journal of Community Health, v. 20, n. 4, p. 321-335, 1995.

PARATHASARATHY, S. Building genetic medicine; breast cancer, technology and the comparative politics of health care. Cambridge: MIT Press, 2007.

RABINOW, P. 'Artificiality and Englightenment' from sociobiology to biosociality. In: J. Crary, \& S. Kwinter (Eds.), Zone 6: Incorporations. New York: Zone, 1996.

RAPP, R. Testing women, testing the fetus: The social impact of amniocentesis in America. New York: Routledge, 1999.

RICHARDS, M. Lay and professional knowledge of genetics and inheritance. Public Understanding of Science, $n$. 5, p. 217-230, 1996.

ROLL, I. V.; SIMMS, V.; HARDING, R. Multidimensional problems among advanced cancer patients in Cuba: awareness of diagnosis is associated with better patient status. Journal of Pain and Symptom Management, $v$. 37, n. 3, p. 325-330, 2009.

ROSENDHAL, M. Inside the revolution: Everyday life in socialist Cuba Ithaca. NY: Cornell Univeristy Press, 1997.

ROSE, N.; NOVAS, C. Biological citizenship. In: ONG, A.; COLLIER, S. (Org.). Global assemblages; technology, politics and ethics as anthropological problems. (pp. 439e463). 0xford: Blackwell, 2005, p. 439-463.

SHAW, A. Conflicting models of risk' clinical genetics and British Pakistanis. In P. Caplan (Ed.), Risk Revisted. London and Sterling. Virginia: Pluto Press, 2000.

SHAW, A. Negotiating genetic risk: British Pakistani experiences of genetics. Oxford and New York: Berghahn Books, 2009.

SILVERMAN, C. Brains, pedigrees and promises: lessons from the politics of autism genetics'. In: GIBBON, S.; NOVAS, C. (Eds.). Biosocialities, identity and thesocial sciences; making biologies and identity. London: Routledge, 2008.

SLEEBOM-FAULKNER, M. (Ed). The frameworks of choice: Predictive and genetic testing in Asia. University of Amsterdam Press, 2010.

SONTAG, S. Illness as metaphor: And, AIDS and its metaphors. London: Penguin, 1991.

SPIEGEL, J.; YASSI, A. Lessons from the margins of globalization: appreciating the Cuban health paradox. Journal of Public Health Policy, v. 25, n. 1, p. 85-110, 2004. 
STACEY, J. Teratologies: A cultural study of cancer. London: Routledge, 1997.

TERUEL, B. M. Cuba's national medical genetics program. MEDICC Review, v. 11, n. 1, p. 11-13, 2009.

WEINER, K. Exploring genetic responsibility for self, family, kin in the case of hereditary raised cholesterol. Social Science \& Medicine, n.72, v.11, p.1760-1767, 2010. 